\title{
Construction of Inductive Explanation Technology in Multimedia Teaching System of Introduction to Physical Education
}

\author{
http://dx.doi.org/10.3991/ijet.v11i09.6122 \\ Zhengmei Jin, Youguo Shi * \\ Bengbu Medical College, Bengbu, Anhui, China
}

\begin{abstract}
-rapid development of multimedia teaching technology makes modern teaching forms more and more diversified. Especially in recent years, mutual integration of some new technologies and multimedia technology has improved diversity of multimedia teaching ecological system. Based on the above background, this paper designed a multimedia teaching system based on inductive technology. This system takes SCM, CAN bus and sensor technology as the core and forms a full set of intelligent and inductive multimedia teaching platform through construction of peripheral circuit. This paper adopted experiment teaching method to study the application of this system in the course of Introduction to Physical Education. The results verify that, this system has a significant effect on improving students' learning interest, active thinking ability, generalization and summarization ability, and examination scores, so it can be further promoted in other courses of college PE specialty.
\end{abstract}

Index Terms - Introduction to Physical Education, inductive explanation technology, multimedia teaching

\section{INTRODUCTION}

Multimedia technology is a modern audio-visual technology which integrates multiple media such as text, picture, voice and video and synthesizes them into multiple media forms. Its most prominent feature is that, computer technology and audio-visual technology are organically combined to derive a brand-new sense organ deduction technology [1]. From 1990s, multimedia technology started to be known by people. As PPT, Authorware [2] and other software as well as hardware systems such as electronic whiteboard all-in-one machine improve continuously, multimedia technology gradually becomes the most important demonstration platform if education, teaching and teleconference etc. In recent years, integration of multimedia technology and intelligent induction technology and construction of new multifunctional multimedia teaching system have increasingly become the research hotspot. Research achievements of relevant scholars also spring up continuously [3].

Tsai et al. [4] carried out multimedia teaching experiment in the course of Water Engineering Science and Living Technology. Based on multimedia, they combined the augmented reality application of multimedia technology in teaching aquatic organisms. Users considered such multimedia teaching mode characterized by teaching information capacity and interactive user interface could improve learning interest. King [5] offered the results of an action research project which aimed to confirm the effect of instructional DVD on multimedia teaching sports therapy injury assessment skills. It is found that such mixed teaching can improve teaching effect. Preece [6] introduced the application of 3D animation induction multimedia technology in medicine. The results indicate that physical models may have a significant advantage over alternative resources in enhancing visuospatial and 3D understanding of complex anatomical architecture, and 3D computer models have significant limitations as for 3D. Wang [7] studied an intelligent voice multimedia explanation system based on RFID induction technology. This system can achieve remote and wireless induction explanation functions and is applied in museum sightseeing explanation. $\mathrm{Fu}$ [8] explored a virtual reality multimedia interaction platform. This platform, based on virtual induction technology, has diversified functions such as virtual museum, virtual control board and motion sensing game.

Although the above scholars focus on different research emphases, they all explored a new system which integrates induction technology and multimedia technology. However, it is easily found from existing researches that, existing induction multimedia explanation technology is rarely applied in Interlocution of Physical Education of college PE specialty. Most multimedia technologies applied in college PE specialty are traditional multimedia technologies which are based on PPT and only have demonstration function, without automatic explanation, intelligent induction and report deduction functions. Thus, function expansion of existing multimedia technology applied in college PE course is significantly insufficient [9]. On this basis, this paper developed and applied inductive explanation multimedia teaching system. This system not just owns functions of traditional multimedia teaching equipment, but also has multiple functions including intelligent induction, automatic explanation and report deduction etc. Hence, it has positive value for improving and innovating functions of existing multimedia teaching system.

\section{OVERVIEW OF SYSTEM DESIGN}

\section{A. Teaching design need}

To effectively solve the above problem, this paper designed a multimedia teaching system based on induction technology. The system has the following advantages: (1) own functions of traditional multimedia teaching platform and other functions such as body induction, automatic explanation, loop playback and automatic storage; (2) based on traditional multimedia teaching system, sound intelligent induction multimedia teaching system is 
constructed by applying EST527 module, SCM, LCD, infrared ray and other electronic information technologies; (3) its application in teaching Introduction to Physical Education can effectively improve defects of traditional multimedia teaching system and boost teaching efficiency and students' experience feeling.

\section{B. System composition modules}

Based on traditional multimedia teaching system, sound intelligent induction multimedia teaching system is constructed by applying EST527 module, SCM, LCD, infrared ray and other electronic information technologies. Figure 1 shows composition modules of this system.

As shown in the figure 1 , this system consists of four parts: multimedia demonstration playing screen, master control module, SCM control module and EST527 module.

(1) Multimedia demonstration playing screen: mainly used to display teaching information content, including image, text, video and animation etc.

(2) Master control module: its core device is LPC2478ARM microcontroller by which users can select and control functions of each SCM control module through connection with button circuit and LCD circuit.

(3) SCM control module: its core device is AT89C52 SCM. This module has built-in teaching content of each chapter of Introduction to Physical Education. It is connected through peripheral sensor, LCD touch screen, storage downloading circuit and speech circuit. It can play relevant teaching content according to the existence of students or students' independent choice demand.

(4) EST527 module: EST527 module is used to communication connection among each sub-module.

It is known from figure 2 that, the connection of multimedia teaching based on induction explanation technology is composed of large screen projection classroom, Induction explaining device, Induction controller 1, Induction controller 2, Power amplifier, Sound, Classroom lighting and Multimedia screen.

\section{System operation process}

Based on the above composition module, this system can operate according to figure 3 in the specific teaching application.

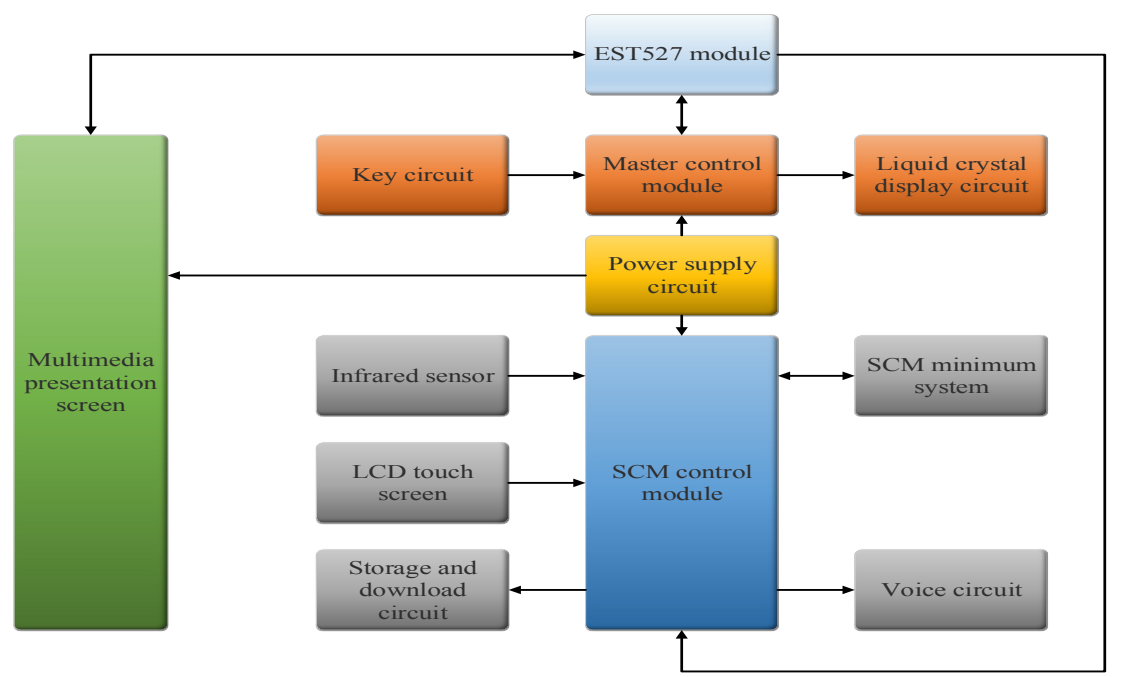

Figure 1. Composition of multimedia teaching based on induction explanation technology

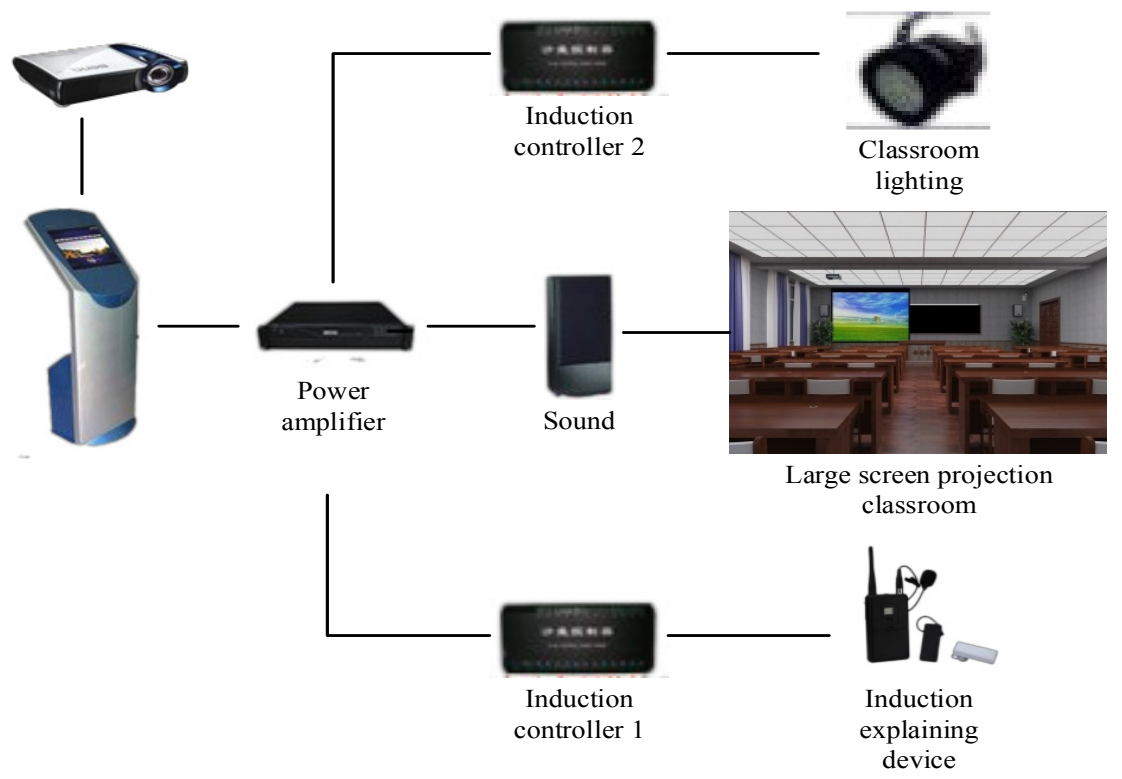

Figure 2. Connection of multimedia teaching based on induction explanation technology 
PAPER

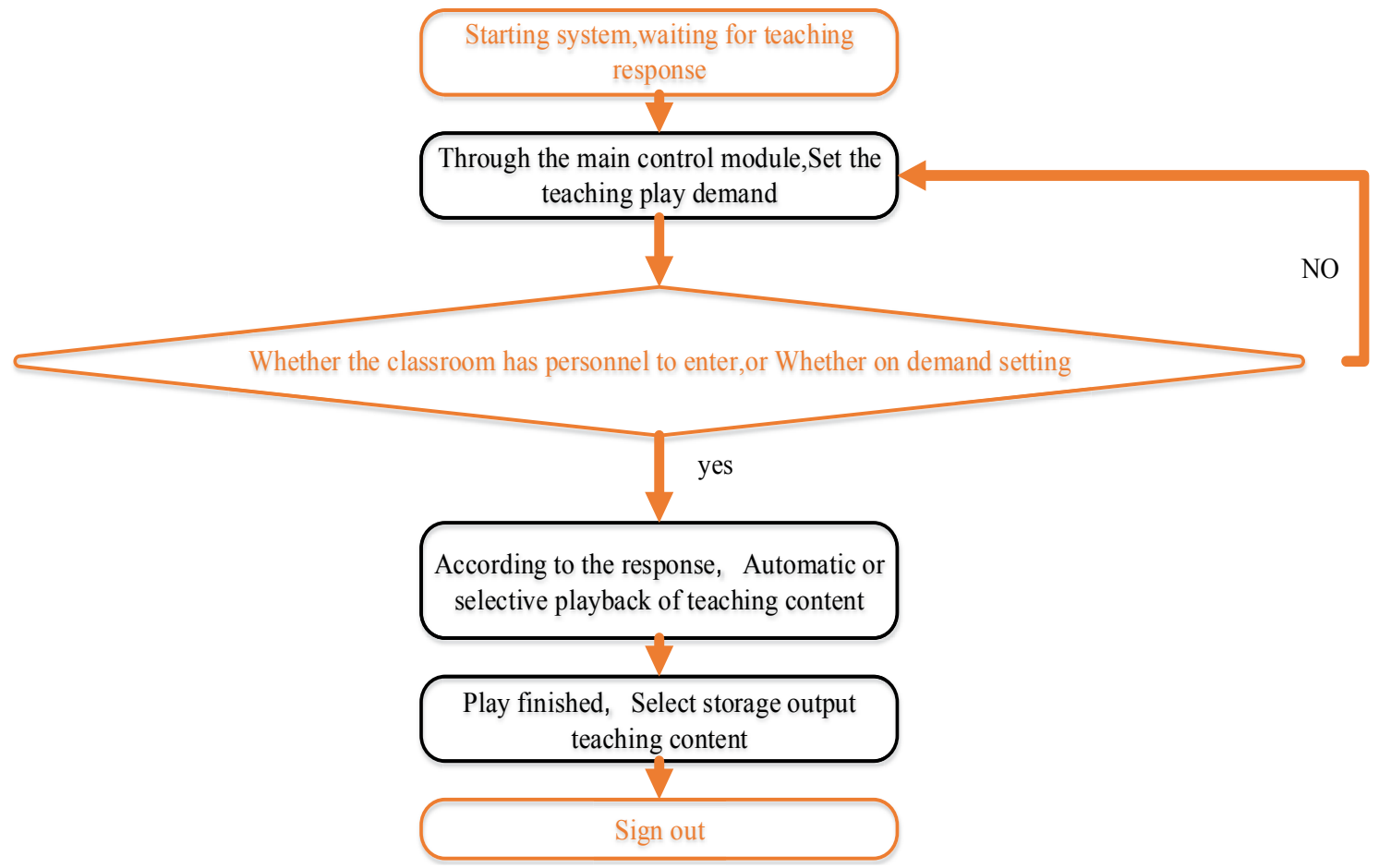

Figure 3. Application process of multimedia teaching based on induction explanation technology

This system operates according to the above process when it is applied in teaching. When the system is in the working state, infrared technology can be used to detect the response of on-site teaching environment. The detection contents mainly include: whether there are people entering the site; or whether there is teaching playing setting demand. Once one of two conditions is met, the system will play corresponding teaching content according to the response. In the playing process, if teachers or students have loop playback and selective playing demands, they can set through the button on the touch screen. When all teaching contents are played, teachers or students may click storage downloading button to download teaching courseware, and finally click "exit" button to $\log$ off.

\section{ANALYSIS OF TEACHING EXPERIMENT}

\section{A. Teaching objects}

Students in Class (1) and Class (2) of 2013 physical education specialty were chosen as the objects. Each class included 50 students, and the two classes had no significant statistical difference in the age, gender and learning ability $(\mathrm{P}>0.05)$. In the specific teaching experiment, Class (1) served as the control class, and Class (2) served as the experimental class.

\section{B. Teaching design}

In teaching design scheme, the required course of PE specialty - Introduction to Physical Education was chosen as the content, including 36 class hours. To highlight the teaching value of inductive explanation multimedia system, this system was adopted for the experimental class, while traditional multimedia system was used for the control class. After the course ended, learning interest, knowledge mastery, active thinking ability, gains and final examination scores of students in both class were collected and recorded, and teaching effects were compared.

\section{Statistical method}

SPSS13.0 software was applied for sample analysis of each learning index. $\mathrm{P}<0.05$ means the difference has statistical significance. Besides, EXCEL software was used to make corresponding statistical data into graphs for analysis so as to make teaching evaluation results clear at a glance.

\section{Implementation of teaching}

\section{1) Implementation strategy of control class}

During teaching the control class, the teacher applied traditional teaching method. The detailed teaching mode was that: blackboard and multimedia courseware served as the teaching carriers, and teaching by personal example as well as verbal instruction, PPT presentation, question answering in classroom and assignment arrangement were comprehensive applied to implement teaching.

\section{2) Implementation strategy of experimental class}

During teaching the control class, the teacher took inductive explanation multimedia teaching system as the main auxiliary equipment and focused on relevant knowledge points of Introduction to Physical Education for teaching practice. The detailed teaching process is as follows:

Firstly, classroom explanation link. In this link, the teacher used traditional teaching form to explain knowledge points of Introduction to Physical Education. The chapter of "status of PE in modern social life" was taken for example. The teacher mainly explained relevant content for students through traditional PPT equipment in the form of static pictures and texts. Secondly, the teacher brought the experiment class in inductive explanation teaching experience pavilion which was built by focusing on multimedia teaching system based on inductive explanation. There are 8 experience sub-pavilions including AT89C52 SCM module and multimedia demonstration 
module which were connected through EST527 module and master control module. In the detailed practice, the teacher divided students into 8 groups according to their question type, learning ability and interest. Course exhibition content was set through master control module, and each group was arranged to enter the corresponding experience pavilion for independent appreciation-based learning. In the whole process, each group could speed, pay a return visit to and select the learning content through touch screen control function on SCM module according to their needs. The all contents were mainly presented in the form of vivid and interesting dynamic pictures and videos, as shown in figure 4 and figure 5.

\section{RESULTS AND Discussions}

\section{A. 4.1 Teaching results}

After the teaching lasting for 36 class hours ended, the teacher collected and sorted various learning indexes of experimental class and control class, and compared teaching effects. $\mathrm{P}<0.05$ marks the results have statistical difference. The detailed statistical results are shown in Tables I and II.

It is known from Table I and Table II that, firstly, for examination scores, statistical difference between experimental class and control class is very significant. The experimental class is significantly superior to the control class regardless of theory examination score and practice examination score $(\mathrm{P}<0.05)$. Secondly, for the findings, various indexes of experimental class are also significantly superior to those of control class. Especially for "knowledge mastery", excellent rate of experimental class reaches $90 \%$, while excellent rate of control class is only $55 \%$. This indicates that inductive explanation technology contributes to improving students' knowledge capability of Introduction to Physical Education and has positive teaching effect.

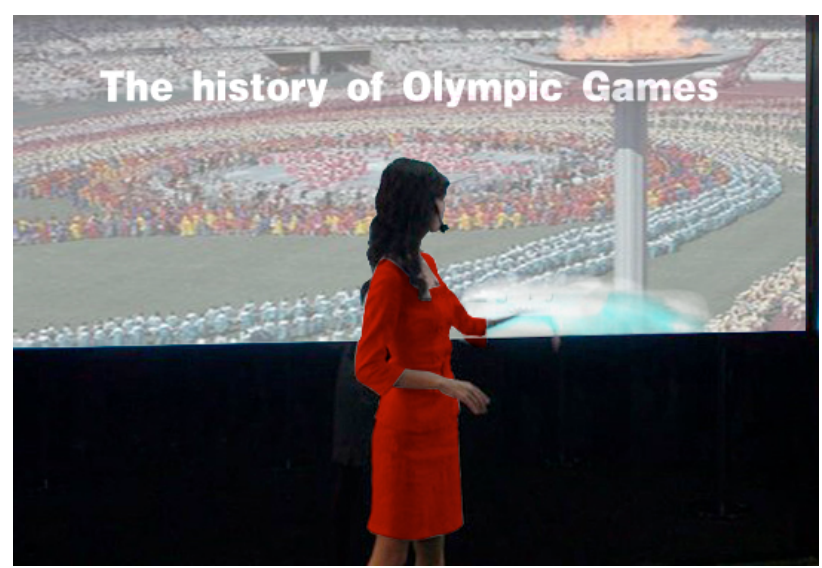

Figure 4. Exhibition of Introduction to Physical Education with inductive explanation technology

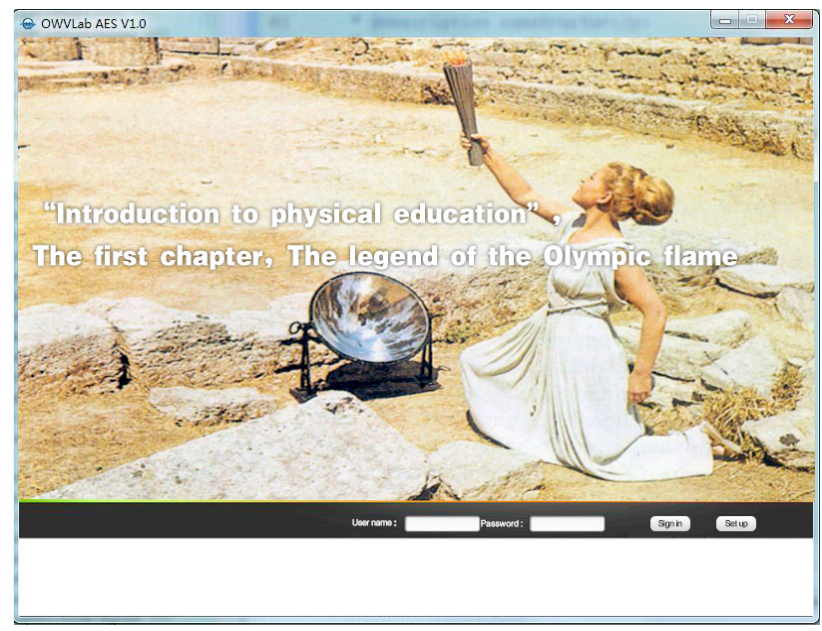

Figure 5. Multimedia teaching login interface of Introduction to Physical Education

TABLE I.

EXAMINATION SCORE COMPARISON OF CONTROL CLASS AND EXPERIMENTAL CLASS (SCORE, , $\mathrm{X}+\mathrm{S}$ )

\begin{tabular}{|l|c|c|}
\hline \multicolumn{1}{|c|}{ Class } & Theory examination score & Practice examination score \\
\hline Experimental class & $92.34 \pm-6.54$ & $88.21_{-}^{+5.32}$ \\
\hline Control class & $71.67 \pm 3.22$ & $65.76+4.12$ \\
\hline $\mathrm{t}$ & -2.445 & -3.567 \\
\hline $\mathrm{p}$ & 0.001 & 0.003 \\
\hline
\end{tabular}

TABLE II.

QUESTIONNAIRE SURVEY RESULT COMPARISON OF CONTROL CLASS AND EXPERIMENTAL CLASS (\%)

\begin{tabular}{|c|l|c|c|c|c|c|}
\hline \multirow{2}{*}{ Class } & \multicolumn{1}{|c|}{ Class } & Learning interest & Knowledge mastery & Active thinking ability & $\begin{array}{c}\text { Generalization and summariza- } \\
\text { tion ability }\end{array}$ & Gains \\
\hline \multirow{4}{*}{ Experimental class } & Good & 85 & 90 & 75 & 80 & 87 \\
\cline { 2 - 7 } & General & 10 & 5 & 15 & 15 & 10 \\
\cline { 2 - 8 } & Poor & 5 & 5 & 10 & 5 & 3 \\
\hline \multirow{3}{*}{ Control class } & Good & 45 & 55 & 40 & 30 & 30 \\
\cline { 2 - 8 } & General & 25 & 30 & 25 & 35 & 10 \\
\hline
\end{tabular}




\section{B. Discussions}

Introduction to Physical Education is a required course of college PE specialty, and aims to train qualified PE workers, deepen students' cognition of theory and practice of PE, make students master basic rules of PE and improve their ability to analyze and solve relevant problems with the knowledge of PE specialty. At present, most teachers adopt traditional multimedia teaching form to organize teaching practice in teaching Introduction to Physical Education. Such mode is dominated by teacher's PPT presentation and on-site explanation, and assisted by students' viewing. In the whole teaching process, students' initiative cannot be effectively mobilized, and teaching effect is not high.

Compared with traditional multimedia teaching form, Introduction to Physical Education teaching based on inductive explanation technology has three significant features: (1) achieve cycle teaching. After basic cognition learning, students can enter inductive explanation multimedia teaching training room and learn difficult and key contents; (2) improve learning experience. This system adopts intelligent technologies such as body pyroelectric sensor, SCM and EST527 module to construct a multimedia teaching system with stronger dynamic sense, viewing sense and intelligent sense. Students can feel automatic and intelligent learning effect, and their learning experience is richer; (3) stronger learning sharing summary. This system can not just achieve course viewing and independent learning, but can download stored learning courseware and effectively help students for review. Hence, modern and information-based review system is constructed. Therefore, the teaching effect is better, with this system.

Based on the above three features, the students in the experimental class feel more diversified learning experience than the students in the control class, while the learning process with stronger dynamic sense and inelegant sense exactly motivate their learning interest and driving force. Data statistics in Table I and Table II speaks volumes for this. In addition, it is found from the interview with the students in the experimental class that, more than $95 \%$ of students express that inductive explanation multimedia system is more advanced than traditional multimedia system. The teaching mode designed by the teacher on the basis of this system is very vivid. The whole learning proves makes them interested. Hence, this system has positive significance for improving their examination scores.

\section{CONCLUSION}

This paper designed and applied inductive explanation multimedia system. The inductive explanation multimedia system shows that, this system is very superior in terms of teaching advancement, intelligence, viewing and interaction, so it plays a great role in improving teaching effect of
Introduction to Physical Education. Therefore, it is suggested that this teaching system should be generalized and applied in other courses of college PE specialty.

\section{REFERENCES}

[1] Hermes M., King K.A., “Ojibwe Language Revitalization, Multimedia Technology, and Family Language Learning," Language Learning \& Technology, vol. 17, no. 1, pp. 125-144, February 2013.

[2] Robbins R.N., Mellins C.A., Leu C.S., et al., "Enhancing Lay Counselor Capacity to Improve Patient Outcomes with Multimedia Technology," Aids \& Behavior, vol. 19, no. 2, pp. 1-14, June 2015.

[3] Harris A.L., Medlin D., Dave D.S., "Multimedia Technology as a Learning Tool: A Study of Demographic and Cultural Impacts," Journal of Computer Information Systems, vol. 36, no. 4, pp. 1821, February 2016.

[4] Tsai C.H., Yen J.C., "The Augmented Reality Application of Multimedia Technology in Aquatic Organisms Instruction," Journal of Software Engineering \& Applications, vol. 7, no. 9, pp. 745755, January 2014. http://dx.doi.org/10.4236/jsea.2014.79069

[5] King C.D., Lawrence L.A., Mackinnon G.R., "Using Multimedia Technology in Jamaican Athletic Training Education: A CaseBased Learning Approach," Journal of Applied Learning Technology, vol. 4 no. 2, pp. 40-49, April 2014.

[6] Preece D., Williams S.B., Lam R., et al., "'Let's get physical': advantages of a physical model over 3D computer models and textbooks in learning imaging anatomy," Anatomical sciences education, vol. 6, no. 4, pp. 216-224, January 2013. http://dx.doi.org/10.1002/ase.1345

[7] Wang Z.K., "An inductive intelligent voice explanation system based on RFID," Computer Applications and Software, vol. 29, no. 6, pp. 242-243, 270, June 2012.

[8] Fu L., "Analysis of multimedia interactive design based on virtual reality," Journal of Beijing Institute of Graphic Communication, vol. 21, no. 1, pp. 15-17, February 2013.

[9] Wu D., "Analysis of PE multimedia teaching based on information-based teaching environment," Contemporary Sports Technology, vol. 4, no. 14, pp. 58-59, May 2014.

[10] Huang X., Cheng F., "Study on prospect and effect of multimediaassisted PE," Bulletin of Sport Science and Technology, vol. 21, no. 9, pp. 130-131, September 2013.

\section{AUTHORS}

Zhengmei Jin is a Lecturer of Bengbu Medical College, Bengbu 233030, Anhui, China. Her research interests include physical education, Inductive Explanation Technology and Multimedia Teaching. (13721181220@163.com)

Youguo Shi (Corresponding author) is a Lecturer of Department of Physical Education and Art, BengBu Medical College, Bengbu 233030, Anhui, China. His research interests include Sports Economics and Multimedia courseware. (shiyouguo1234@yeah.net)

This work was supported by the humanities and social science research project of Anhui Provincial Department of Education (Sk2015b09by). The authors declare that there is no conflict of interests. Submitted 07 August 2016. Published asresubmitted by the authors 15 September 2016. 